\title{
Fosfor plak kullanılarak farklı kaide materyallerinin radyoopasitelerinin karşılaştırılması
}

\author{
Osman Sami Ağlarcı', Gökçe Garip ${ }^{2}$, Evren $\mathrm{Ok}^{3}$, Mustafa Altunsoy²
}

Selcuk Dental Journal, 2015; 1: 7-12

Bașvuru Tarihi: 25 Mart 2015

Yayına Kabul Tarihi: 16 Nisan 2015

\section{Evaluation of radio-opacity of different base materials using digital phosphor plate}

Background: The radiopacity of cavity base materials has been considered as an important requirement, improving the radiographic diagnosis. The advantages of radiopacity over radiolusent materials are the easy detection of recurrent dental caries and observation of the radiographic interface between the materials and tooth surfaces. This study aims to investigate the radiopacity of glass ionomer cements (GICs) and flowable resin composites (FRCs) using a digital phosphor plate, comparing them to the dental tissues (enameldentine), expressed as equivalent thickness of aluminum.

Methods: Three disk-shaped specimens, $10 \mathrm{~mm}$ in diameter and 1 $\mathrm{mm}$ in thickness were prepared for each material. Specimens of enamel and dentine with the same thickness were obtained as a control. After setting of the base materials, specimens were placed on a phosphor plate together with aluminum step-wedge ( 1 to $16 \mathrm{~mm}$ in thickness ) and were exposed using a dental x-ray unit. Three measurements of radiographic density were obtained from each image of each item assessed ( base material, enamel, dentin, each step of the aluminum step-wedge) and the mean of these values was calculated. Radiopacity values were later calculated as equivalents of aluminum thickness. Data were analyzed by ANOVA and Tukey's test.

Results: As the Vertise Flow is the only material that showed higher radiopacity than enamel, other materials presented significantly lower radiopacity than it $(p<0.005)$. Vertise Flow, Nova Glass-F and Equa Fil showed significantly higher radiopacity than dentine $(p<0.005)$. However, no significant difference in radiopacity was observed between G-aenial Universal Flo, lonoseal and dentine ( $p>0.05)$.

Conclusion: Equia Fil, Nova Glass-F, and Vertise Flow have higher radiopacity than dentin. However radiopacity value of base materials varies considerably. So this should be taken seriously when selecting materials.

\section{KEY WORDS}

Dental materials, flowable composite, glass iyonomer cement, radioopacity

\footnotetext{
${ }^{1}$ Şifa Üniversitesi Diş Hekimliği Fakültesi Ağız, Diş ve Çene Radyolojisi Anabilim Dalı

2 Şifa Üniversitesi Diş Hekimliği Fakültesi Pedodonti Anabilim Dalı

3 Şifa Üniversitesi Diş Hekimliği Fakültesi Endodonti Anabilim Dalı
}

Restorasyonlarda kullanılan dental materyallerin radyoopasitesi, özellikle posterior dişleri ilgilendiren radyografik tanılarda son derece önemli bir unsurdur (Imperiano 2007). Yeterli radyoopasiteye sahip materyal sekonder çürüklerin teşhisini ve radyografide çürüğün restoratif materyalden ve diş dokusundan ayrıımasını sağlar. Bununla birlikte marjinal defektler, taşkınlıklar ve açık marjinler gibi durumların yanında pulpaya yakınlığın da kolaylıkla görüntülenebilmesini kolaylaştııır (Bouschlicher ve ark 1999).

Son yillarda, kaide materyali olarak cam iyonomer ve rezin esaslı materyaller sıkça kullanılmakta ve üreticiler tarafından doldurucular veya radyoopak bileşenler eklenerek radyoopasiteleri arttıılmaya çalışılmaktadır (Marouf ve Sidhu 1998). İdeal klinik performans için ihtiyaç duyulan radyoopasite derecesi materyalin türüne göre değişiklik göstermektedir (Hara ve ark 2001). Radyoopasite ile ilgili çalışmalar genellikle mine, dentin ve alüminyum (Al) ile kıyaslanarak yapılmaktadır (Ergucu ve ark 2010). Bazı yazarlara göre materyalin radyoopasitesi dentinin radyoopasitesinden büyük ya da eşit olmalıdır (el-Mowafy ve Benmergui 1994, Turgut ve ark 2003). Bazı yazarlar ise restoratif materyallerin mineden daha yüksek 
veya eşit radyoopasiteye sahip olması gerektiğini düşünmektedirler (Bowen ve Cleek 1972, Akerboom ve ark 1993). Uluslararası Standartlar Örgütü protokolüne göre dental materyalin radyoopasitesi, optik yoğunluk değeri olarak veya referans kalibrasyon eğrisi kullanılarak elde edilen eşdeğer alüminyum kalınlığı (milimetre) açısından ifade edilmektedir. $\mathrm{Bu}$ materyallerin radyoopasitelerinin alüminyuma eşit veya büyük olması tavsiye edilmektedir (Watts ve McCabe 1999).

Farklı restoratif materyallerle yapılan çalışmalarda test edilen materyaller arasında radyoopasitede dikkate değer farklılıklar gözlemlenmiştir (Williams ve Billington 1987, Goshima ve Goshima, 1991, Bouschlicher ve ark 1999, Murchison ve ark 1999). Bu görüntüler dijital radyografilerden yararlanılarak spesifik bilgisayar programına göre direk veya indirek metotla elde edilebilmektedirler (Gürdal ve Akdeniz 1998). Dijital görüntüleme sistemleri; kısa ışınlama süresi, hızlı ve kolay kullanımı ve net radyoopasite değerlendirmesine izin vermesi nedeniyle klinik uygulamalarda konvansiyonel radyografik sistemlere göre avantajlar içermektedir (Versteeg ve ark 1997). Bu nedenle laboratuvar araştırmalarında dental materyallerin radyoopasitelerinin değerlendirilmesinde sıkça kullanılmaktadırlar. Bu sistem ile radyograf, bilgisayar yazılımına uygun hale getirilerek, her maddenin 0 (siyah) ile 255 (beyaz) arasında değişen skalada ortalama grilik değerleri (Mean Gray Value-MGVs) belirlenmektedir (Lachowsk ve ark 2013).

Bazı cam iyonomer esaslı ve rezin esaslı kaide materyallerinin klinik çalışmalarda yetersiz radyoopasiteye sahip olduğu görülürken, dental materyallerin radyoopasitelerinin değişkenlik gösterdiği çalışmalar da bildirilmiştir (Ergucu ve ark 2010). Bu çalışmada cam iyonomer ve rezin esaslı farklı kaide materyallerinin radyoopasiteleri incelenerek; bunların mine, dentin ve saf alüminyum basamak radyoopasiteleri ile karşılaştırılması amaçlandı.

\section{GEREÇ ve YÖNTEM}

Bu çalışmada 5 farklı kaide materyali ile mine ve dentinin radyoopasiteleri test edilmiştir. Çalışmada kullanılmak üzere restoratif diş hekimliği klinik uygulamalarında sıklıkla kullanılan materyaller seçilmiştir. Bu çalışmada değerlendirilen 5 kaide materyali Tablo 1'de listelenmiştir.
Tablo 1.

\section{Çalışmada kullanılan materyaller}

\begin{tabular}{|lll|}
\hline Materyaller & Materyal tipi & Üretici firma \\
\hline Nova Glass-F & $\begin{array}{l}\text { Restoratif cam } \\
\text { iyonomer siman }\end{array}$ & $\begin{array}{l}\text { Imicryl, Konya, } \\
\text { Türkiye }\end{array}$ \\
\hline Equia Fil & $\begin{array}{l}\text { Restoratif cam } \\
\text { iyonomer siman }\end{array}$ & $\begin{array}{l}\text { GC Europe, Leuven, } \\
\text { Belçika }\end{array}$ \\
\hline lonofil & $\begin{array}{l}\text { Restoratif cam } \\
\text { iyonomer siman }\end{array}$ & $\begin{array}{l}\text { Voco Gmbh, } \\
\text { Almanya }\end{array}$ \\
\hline Vertise Flow & $\begin{array}{l}\text { Işıkla sertleşen } \\
\text { kendinden adezivli } \\
\text { akışkan kompozit }\end{array}$ & $\begin{array}{l}\text { Kerr Co, Orange, } \\
\text { CA, ABD }\end{array}$ \\
\hline $\begin{array}{l}\text { G-aenial } \\
\text { Universal Flo }\end{array}$ & $\begin{array}{l}\text { Işıkla sertleşen } \\
\text { akışkan kompozit }\end{array}$ & $\begin{array}{l}\text { GC Amerika, IIllinois, } \\
\text { ABD }\end{array}$ \\
\hline
\end{tabular}

Örneklerin hazırlanmasında $10 \mathrm{~mm}$ çapında, $1 \mathrm{~mm}$ kalınlığında plastik disk şekilli kalıplardan yararlanıldı. Cam levha üzerine yerleştirilen kalıplara materyaller dolduruldu. Düz bir yüzey elde etmek için materyallerin üzerine şeffaf bant ve cam levha ile bastırıldıktan sonra üretici firmanın talimatına göre sertleşmeleri tamamlandı. Işıkla aktive olan materyallerin her iki yüzeyine de $40 \mathrm{~s}$ süre ile ışık kaynağı uygulandı. Her materyal için 3 standardize örnek üretici firmanın talimatına göre elde edildi.

Çalışmada, mine ve dentin örnekleri elde etmek için yeni çekilmiş üçüncü molar dişler kullanıldı. Kronlar transversal yönde düşük hızdaki elmas testere ile kesilerek, $1 \mathrm{~mm}$ kalınlığında 3'er örnek olacak şekilde mine ve dentin fragmanları oluşturuldu. Hazırlanan örnekler kullanılana kadar $37^{\circ} \mathrm{C}$ 'deki distile suda bekletildi.

Dokuz basamaklı saf alüminyum basamak, örneklerin densitesinin alüminyum ile olan ilişkisini değerlendirmek için referans olarak kullanıldı.

Dental X ışını cihazı (MyRay, Imola, İtalya) fokal spot mesafesi $30 \mathrm{~cm}$ olacak şekilde $70 \mathrm{kVp}$ ve $7 \mathrm{~mA}$ 'a ayarlandı. Her materyale ait 3 örnek, diş kesitleri ve alüminyum step-wedge fosfor plak üzerine yerleştirildi. Görüntü reseptörü olan fosfor plak özel tarayıcı (DBSWIN Imaging Software, Dürr Dental, Bietigheim-Bissingen, Almanya) ile tarandıktan sonra görüntü bilgisayar monitöründe izlendi.

Örneklerin radyoopasitelerinin dijital radyograflarla belirlenmesinin ardından görüntüler Image $J$ (National Institutes of Health, Maryland, ABD) yazılımına aktarıldı. $\mathrm{Bu}$ program görüntünün merkezinde belirli bir alanı imleç ile sınırlandırarak MGV'nin elde edilmesini sağlamaktadır. Ayrıca örneklerin en yüksek, en düşük ve ortalama radyoopasite (MGV) değerlerini göstermektedir. Program ile her örnekten üç ölçüm (her materyal için 9 ölçüm) yapılarak değerlerin ortalaması hesaplandı. Hesaplanan 
değerler Vivan ve ark (2009) tarafından önerilen denklem kullanılarak milimetre alüminyuma $(\mathrm{mmAl})$ dönüştürüldü:

$\frac{A-B}{C-B} x$ Örnek Kalınlığ $l+$ Materyalin $M G V^{\prime} \operatorname{sinin}$ altındaki $m m A l$

Bu denklemde; A materyalin MGV'si, B materyalin MGV'sinin hemen altındaki saf alüminyum basamak artışının MGV'si, C materyalin MGV'sinin hemen üzerindeki saf alüminyum basamak artışının MGV'si olarak hesaplanır.

Çalışılan her materyalin milimetre alüminyum cinsinden radyoopasitelerini karşılaştırmak için varyans analizi (ANOVA), ikili karşılaştırmalar için Tukey testinden $(\alpha=0,05)$ yararlanıldı. $\mathrm{Bu}$ analizlerden sonra grupların radyoopasiteleri mine ve dentinin radyoopasitesi ile kıyaslandı.

\section{BULGULAR}

Cam iyonomer ve rezin esaslı kaide materyallerinin, minenin ve dentinin radyoopasite değerleri Tablo 2'de sunulmuştur. Vertise Flow mineden yüksek radyoopasite değeri gösteren tek materyal olurken, diğer materyaller Vertise Flow'dan istatistiksel olarak belirgin ölçüde düşük radyoopasite değeri göstermişlerdir $(p<0,05)$. Bununla birlikte, Vertise Flow, Nova Glass-F ve Equia Fil dentinden belirgin ölçüde yüksek radyoopasite değeri gösterirken $(p<0,05)$, lonofil ve G-aenial Universal Flo dentin ile benzer radyoopasite değeri göstermiştir $(p>0,05)$. Materyallerin kendi içlerindeki radyoopasiteleri değerlendirildiğinde; cam iyonomer içerikli kaide materyallerinin radyoopasite değerleri istatistiksel olarak benzer görülürken $(p>0,05)$, rezin esaslı kaide materyalleri birbirlerinden belirgin ölçüde farklı değerler göstermiştir $(p<0,05)$.

Tablo 2.

Alüminyum kalınlığına eş değer olarak ifade edilen radyoopasite değerleri

\begin{tabular}{llllll} 
Materyaller & $\mathbf{N}$ & $\begin{array}{l}\text { Ortalama } \\
\text { radyoopasite } \\
\text { (mmAl) }\end{array}$ & Minimum & Maksimum & $\begin{array}{l}\text { Gruplar } \\
\text { (Tukey) }\end{array}$ \\
\hline Vertise Flow & 9 & 5,0089 & 4,76 & 5,24 & $\mathrm{~A}$ \\
\hline Mine & 3 & 3,3967 & 3,26 & 3,49 & $\mathrm{~B}$ \\
\hline Equia Fil & 9 & 2,4056 & 2,16 & 2,69 & $\mathrm{C}$ \\
\hline Nova Glass-F & 9 & 2,2644 & 2,09 & 2,44 & $\mathrm{CD}$ \\
\hline İonofil & 9 & 2,12 & 2,06 & 2,25 & $\mathrm{CDE}$ \\
\hline $\begin{array}{l}\text { G-aenial } \\
\text { Universal Flo }\end{array}$ & 9 & 1,9044 & 1,82 & 2 & $\mathrm{DE}$ \\
\hline Dentin & 3 & 1,7467 & 1,72 & 1,77 & $\mathrm{E}$
\end{tabular}

\section{TARTIŞMA}

Restoratif materyallerin uygun radyoopasitesiye sahip olması materyal için önemli bir intiyaç olarak düşünülmektedir. Çünkü bu sayede materyalin renk kalitesinin önemli göstergesi olan ışık penetrasyonu ve yansıması derecesi düzenlenmektedir

(Santos

1999).

Radyoopasite mine/dentin ve restoratif materyal arasında uygun kontrast sağlayarak, tekrarlayan çürüklerin, hatalı proksimal kontürlerin ve uyumsuz marjinal kenarların teşhisini kolaylaştırmaktadır (Espelid ve ark 1991, Aguiar 1998). Tekrarlayan çürüklerin varlığı restorasyonların değiştirilmesini gerektiren ana sebeplerden biridir (Braga ve ark 2007). Bu nedenle doğru teşhis için kaide materyalleri sekonder çürüklerle kontrast oluşturabilecek optimal radyoopasiteye sahip olmalı, diş-restorasyon ara yüzeyini diş yapısından ayırt etmeyi kolaylaştırmalıdır (Bouschlicher ve ark 1999).

Restoratif materyallerin radyoopasitesinin aynı kalınlıktaki mine/dentin ve saf aliminyum basamak radyoopasitesi ile klyaslanarak değerlendirilmesi önerilmektedir (Cook 1981, Williams ve Billington 1987). Materyallerin, minenin ve dentinin radyoopasiteleri milimetre cinsinden alüminyum eş değeri olarak ifade edilmektedir. Bizim çalışmamızda Vivan ve ark (2009) tarafından önerilen denklemden yararlanılarak MGV (Mean Gray Value) değerleri mmAl'a çevrilmiştir.

Restoratif materyallerin radyoopasiteleri ISO 4049 standartlarılyla (Standardization 1985) uyumlu olmalıdır. Buna göre materyal, kabul edilebilir alt limit olan, en az aynı kalınlıktaki dentinin radyoopaklığına sahip olmalıdır. Radyoopasitede üst sınır belirlenmemesine rağmen, bazı yazarlar olması gerektiğini düşünmektedir. Amalgam gibi fazla radyoopak materyallerin marjinal adaptasyonun, tekrarlayan çürüklerin ve defektlerin teşhisini azaltabileceği düşünülmektedir (Espelid ve ark 1991, Watts ve McCabe 1999). 
Bu çalışmada net ve güvenilir sayısal veriler sağlayan, iletim densitometresine benzer doğruluk gösterdiği düşünülen dijital görüntüleme analizininden yararlanılmıştır (Ferreira 1999, Gurdal ve Akdeniz 1998). Iletim densitometresinde, film boyunca iletilen gelen ışık oranının logaritmik ölçümü olan optik yoğunluk elde edilmektedir. Dijital görüntüleme analizlerinde ise pikseller 0 ile 255 arasındaki skalada değişen gri tonlara sahip olduğundan, program yardımıyla direk radyografik yoğunluk elde edilebilmektedir (Ferreira 1999). Wenzel ve ark (1998) yaptığı bir çalışmada konvansiyonel intraoral radyografik film ve iki dijital görüntüleme sistemi kullanılarak dental dolgu materyallerinin radyoopasiteleri değerlendirilmiştir. Çalışmanın sonucunda dijital sistemlerin materyallerin radyoopasitelerini ayırt etmede daha az güvenilir olduğu görülmüştür. Bunun yanında dijital sistemlerdeki radyografik yazılım, dijital görüntülerin daha ayrıntılı analizine olanak sağlayarak, bilgisayar ekranında grafiksel verilerin ve gri piksel seviyelerinin değerlendirilmesini kolaylaştııır (Carvalho-Junior ve ark 2007). Ayrıca film geliştirici kimyasallara intiyaç duymaz ve hekimin radyasyona maruz kalma oranını azaltır (Gu ve ark 2006).

Radyoopasite, materyalin içerisine eklenen doldurucuların (gümüş, çinko, baryum, stronsiyum) çeşitliliğine ve miktarına bağlı olarak değişkenlik gösterebilmektedir (el-Mowafy 1998, Rubo 1998). Turgut ve ark (2003) yaptığı bir çalışmada, rezin kompozit içeriğindeki monomerlerin radyolüsent görüntü verirken, doldurucuların farklı opasite değerleri gösterdiğini bildirmişlerdir. Materyallerin radyoopasitelerindeki değişkenliğin temel nedeni olarak içeriklerindeki farklılıklar olduğu düşünülmüştür. Çalışmamızda araştııılan 5 materyalden 3'ünün (Vertise Flow, Equia Fil, Nova Glass-F) dentinden yüksek radyoopasite sergilediği doğrulanmıştır. Diğer ikisi (Ionofil ve G-aenial Universal Flo) ise dentine benzer radyoopasite göstermiştir. Cam iyonomer esaslı kaide materyallerinin radyoopasiteleri ise istatistiksel olarak benzer bulunmuştur. Ayrıca rezin esaslı kaide maddesi olan Vertise Flow'un mineden belirgin ölçüde yüksek radyoopasiteye sahip olduğu belirlenmiştir. Fazla radyoopasiteye sahip olması çürük lezyonlarının gizlenmesine neden olabileceğinden kaide materyali seçimimde uygun seçenek olamayacağı düşünülebilir. Üstelik, düşük radyoopak alanın yanındaki yüksek radyoopasiteli materyal koyu sınırlı alan oluşmasına neden olan görsel illüzyon olarak tanımlanan Match Band etkisine neden olabilmekte ve bu görüntüye hatalı çürük teşhisi konulabilmektedir (Espelid ve ark 1991).

\section{SONUÇ}

Klinik uygulamalarda yapılan restorasyonların yeterliliğini değerlendirebilmek için kullanılan restoratif materyalin ve kaide materyalinin yeterli radyoopasiteye sahip olması önemli bir intiyaçtır. Buna karşılık piyasada yetersiz radoopasiteye sahip bazı kaide materyalleri de mevcuttur. Kaide materyallerinin radyoopasitesini değerlendiren çalışmalar periyodik olarak yapılmalı, daha iyi özellikler elde edebilmek için üreticiler düzenli olarak ürünlerin formulasyonlarını yenilemelidirler. Fosfor plaklar her ne kadar hasta açısından konforlu ve klinisyen için kolay uygulanabilir olsa da, tarama süresi ve sensör ömrü gibi dezavantajlarının aşılması gerekmektedir. 


\section{Fosfor plak kullanılarak farklı kaide materyallerinin radyoopasitelerinin karşılaştırılması}

Amaç: Restorasyonlarda kullanılan dental materyallerin radyoopasitesi sekonder çürüklerin teşhisi, çürüğün restoratif materyalden ve diş dokusundan ayrıması, marjinal defektler, taşkınlıklar, açık marjinlerin tespiti ve pulpaya yakınlığın radyografik tanısında son derece önemli bir unsurdur. İdeal klinik performans için intiyaç duyulan radyoopasite derecesi materyalin türüne göre değişiklik göstermektedir. Radyoopasite ile ilgili çalışmalar genellikle mine, dentin ve alüminyum ile kıyaslanarak yapılmaktadır. Bu çalışmada cam iyonomer ve rezin esaslı farklı kaide materyallerinin radyoopasiteleri incelenerek; bunların mine, dentin ve alüminyum stepwedge'in radyoopasiteleri ile karşılaştırıması amaçlandı.

Gereç ve Yöntemler: Sıklıkla kullanılan 5 kaide materyalinden (Nova Glass-F, Equia Fil, Ionofil, Vertise Flow, G-aenial Universal Flo) $10 \mathrm{~mm}$ çapında, $1 \mathrm{~mm}$ kalınlığında plastik disk şekilli örnekler hazırlandı. Yeni çekilmiş 3.molar dişlerden $1 \mathrm{~mm}$ kalınığında kesit alındı. Bütün örnekler fosfor plak üzerine yerleştirilerek fokal spot mesafesi $30 \mathrm{~cm}$ olacak şekilde $70 \mathrm{kVp}$ ve 7 mAs'e görüntü alındı. Alınan görüntü Image $J$ programına aktarılarak Mean Grey Value ölçüldü. Ölçülen değerin mmAl karşılığı hesaplanarak varyans analizi ve Tukey test ile analiz edildi.

Bulgular: Vertise Flow, Nova Glass-F ve Equia Fil dentinden belirgin ölçüde yüksek radyoopasite değeri gösterirken $(p<0,05)$, l̇onofil ve G-aenial Universal Flo dentin ile benzer radyoopasite değeri göstermiştir $(p>0,05)$. Cam iyonomer içerikli kaide materyallerinin radyoopasite değerleri istatistiksel olarak benzer görülürken $(p>0,05)$, rezin esaslı kaide materyalleri birbirlerinden belirgin ölçüde farklı değerler göstermiştir $(p<0,05)$.

Sonuç: Restoratif materyalin ve kaide materyalinin yeterli radyoopasiteye sahip olması önemli bir intiyaçtır. Buna karşılık piyasada yetersiz radoopasiteye sahip bazı kaide materyalleri de mevcuttur. Kaide materyallerinin radyoopasitesini değerlendiren çalışmalar periyodik olarak yapılmalıdır.

\section{ANAHTAR KELIMELER}

Akışkan kompozit, cam iyonomer siman, dental materyaller, radyopasite

\section{KAYNAKLAR}

Aguiar CMVE, Asfora KK, Santos MCMS, Becerra SRS, 1998. Diagnostico da carie dental. Rev Odontol Univ Santo Amaro, 3, 29-31.

Akerboom HB, Kreulen CM, van Amerongen WE, Mol A, 1993. Radiopacity of posterior composite resins, composite resin luting cements, and glass ionomer lining cements. J Prosthet Dent, 70(4), 351-355.

Bouschlicher MR, Cobb DS, Boyer DB, 1999. Radiopacity of compomers, flowable and conventional resin composites for posterior restorations. Oper Dent, 24(1), 20-25.

Bowen RL, Cleek GW, 1972. A new series of x-rayopaque reinforcing fillers for composite materials. $J$ Dent Res, 51(1), 177-182.

Braga SR, Vasconcelos BT, Macedo MR, Martins VR, Sobral MA, 2007. Reasons for placement and replacement of direct restorative materials in Brazil. Quintessence Int, 38(4), e189-194.

Carvalho-Junior JR, Correr-Sobrinho L, Correr AB, Sinhoreti MA, Consani S \& Sousa-Neto MD, 2007. Radiopacity of root filling materials using digital radiography. Int Endod J, 40(7), 514-520. doi: 10.1111/j.1365-2591.2007.01246.x

Cook WD, 1981. An investigation of the radiopacity of composite restorative materials. Aust Dent J, 26(2), 105-112.

el-Mowafy OM, Benmergui C, 1994. Radiopacity of resin-based inlay luting cements. Oper Dent, 19(1), 11-15.

Ergucu Z, Turkun LS, Onem E, Guneri P, 2010. Comparative radiopacity of six flowable resin composites. Oper Dent, 35(4), 436-440. doi: 10.2341/09-340-L

Espelid I, Tveit AB, Erickson RL, Keck SC, Glasspoole EA, 1991. Radiopacity of restorations and detection of secondary caries. Dent Mater, 7(2), 114-117.

Ferreira FBA, Silva E Souza PAR, Vale MS, Tavano O, 1999. Radiopacidade de cimentos endodonticos avaliados pelo sistema de radiografia digital. Rev Fac Odontologia Bauru, 7, 55-60.

Goshima T, Goshima Y, 1991. Optimum radiopacity of composite inlay materials and cements. Oral Surg Oral Med Oral Pathol, 72(2), 257-260.

Gu S, Rasimick BJ, Deutsch AS, Musikant BL, 2006. Radiopacity of dental materials using a digital X-ray system. Dent Mater, 22(8), 765-770. doi: 10.1016/j.dental.2005.11.004 
Gurdal P, Akdeniz BG, 1998. Comparison of two methods for radiometric evaluation of resin-based restorative materials. Dentomaxillofac Radiol, 27(4), 236-239. doi: 10.1038/sj/dmfr/4600357.

Hara AT, Serra MC, Rodrigues Junior AL, 2001. Radiopacity of glass-ionomer/composite resin hybrid materials. Braz Dent J, 12(2), 85-89.

Imperiano MT, Khoury HJ, Pontual MLA, Montes MAJR, Silveira MMF, 2007. Comparative radiopacity of four low-viscosity composites. Braz J Oral Sci, 6, 1278-1282.

Lachowski KM, Botta SB, Lascala CA, Matos AB, Sobral MA, 2013. Study of the radio-opacity of base and liner dental materials using a digital radiography system. Dentomaxillofac Radiol, 42(2), 20120153. doi: 10.1259/dmfr.20120153.

Marouf N, Sidhu SK, 1998. A study on the radiopacity of different shades of resin-modified glass-ionomer restorative materials. Oper Dent, 23(1), 10-14.

Murchison DF, Charlton DG, Moore WS, 1999. Comparative radiopacity of flowable resin composites. Quintessence Int, 30(3), 179-184.

Rubo MH, el-Mowafy O, 1998. Radiopacity of dualcured and chemical-cured resin-based cements. Int J Prosthodont, 11(1), 70-74.

Santos MCMS,Augiar CM, Khoury H, Braz R, 1999. Avaliacao das radiopacidades dos compomeros Rev Odontol Univ Santo Amaro, 40, 22-25.

Standardization IOF, 1985. ISO Standard 4049: Dental resin-based restorative materials.

Turgut MD, Attar N, Onen A, 2003. Radiopacity of direct esthetic restorative materials. Oper Dent, 28(5), 508-514.

Versteeg $\mathrm{CH}$, Sanderink GC, van der Stelt PF, 1997. Efficacy of digital intra-oral radiography in clinical dentistry. J Dent, 25(3-4), 215-224.

Vivan RR, Ordinola-Zapata R, Bramante CM, Bernardineli N, Garcia RB, Hungaro Duarte MA, de Moraes IG, 2009. Evaluation of the radiopacity of some commercial and experimental root-end filling materials. Oral Surg Oral Med Oral Pathol Oral Radiol Endod, 108(6), e35-38. doi: 10.1016/j.tripleo.2009.07.037.

Watts DC, McCabe JF, 1999. Aluminium radiopacity standards for dentistry: an international survey. J Dent, 27(1), 73-78.
Wenzel A, Hintze H, Horsted-Bindslev P, 1998. Discrimination between restorative dental materials by their radiopacity measured in film radiographs and digital images. J Forensic Odontostomatol, 16(1), 8-13.

Williams JA, Billington RW, 1987. A new technique for measuring the radiopacity of natural tooth substance and restorative materials. J Oral Rehabil, 14(3), 267-269.

Yazışma Adresi:

Dr.Osman Sami AĞLARCI

Şifa Üniversitesi Diş Hekimliği Fakültesi

Ağız, Diş ve Çene Radyolojisi AD

Mansuroğlu Mah. 293/1 Sok No:2

35100 Bayraklı, İzmir

Tel: +90 (532) 5048054

E-mail: aglarci@gmail.com 